\title{
O Uso e a Influência da Tecnologia na Interpretação de Conferências
}

Monografia apresentada no Programa de Pós-Graduação "Formação de Intérpretes de Conferência", da Faculdade de Letras da Pontifícia Universidade Católica do Rio de Janeiro (PUC-Rio)

Orientadora: Prof ${ }^{\mathrm{a}}$ Branca Vianna

Rio de Janeiro 15 de maio de 2012

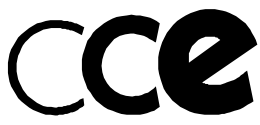

COORDENAÇÃO CENTRAL DE

EXTENSÃO 
A todos aqueles que se dedicam à interpretação de conferências, seja como estudante, professor ou profissional do mercado, ofereço este trabalho como um pequeno guia prático que lhes permitirá entender melhor como a tecnologia pode Ihes ajudar nesta profissão. 


\section{Agradecimentos}

Agradeço ao professor André Bekenn, não apenas por aquilo que ele nos ensinou, mas principalmente por ter-nos instigado sempre a ter curiosidade e a duvidar, em suma, a buscar o conhecimento, ainda que nos pequenos detalhes.

Agradeço à minha professora e orientadora deste trabalho, Branca Vianna, pelos comentários e críticas que me ajudaram a entregar o melhor que eu podia fazer, assim como também pelas suas excelentes aulas, onde pude apreciar como o uso de recursos tecnológicos modernos pode ser de grande utilidade.

Agradeço a todos os demais professores do curso, cuja contribuição à nossa formação foi igualmente importante.

Agradeço à Anna Vianna, ex-aluna do curso e hoje uma profissional reconhecida no mercado, que numa conversa informal me explicou como era esta profissão e me aconselhou a procurar o curso da PUC-Rio.

Agradeço à minha mulher, Elizabeth Pajuaba, por todo o seu apoio e carinho, pela ajuda que me deu para tomar as melhores decisões quando eu estava em dúvida, e por ter sempre sido a minha principal incentivadora nesta nova carreira (talvez não menos importante, também por ter-me ajudado a acordar tão cedo para as aulas do curso); sem dúvida, sem ela este projeto não teria passado de mera conjectura. 


\section{Resumo}

A tecnologia está intimamente relacionada com a interpretação de conferências desde que esta se estabeleceu como profissão reconhecida, durante os anos 30. Desde aquela época, a cabine de interpretação se mostrou a melhor solução como ambiente de trabalho do intérprete. Durante a evolução desta profissão até os dias de hoje, outras soluções tecnológicas foram empregadas para ajudar na formação do intérprete e na sua preparação para eventos. Atualmente, principalmente devido à aceleração do desenvolvimento tecnológico das últimas décadas, existe uma grande variedade de recursos disponíveis para o intérprete, sendo que alguns são mais conhecidos e explorados no meio profissional, enquanto outros menos. No entanto, para poder melhor aproveitar os benefícios que a tecnologia pode trazer, não basta que o intérprete saiba apenas quais são estes recursos e onde eles se encontram, mas também deve compreender os objetivos e as possíveis formas de sua utilização. Além disso, é possível igualmente prever como a rápida evolução tecnológica dos dias de hoje poderá afetar e transformar, num futuro próximo, o exercício desta profissão.

\section{Palavras-Chave}

Interpretação de conferências, a tecnologia e a interpretação, a tecnologia e a formação de intérpretes, a tecnologia e a preparação de eventos, a tecnologia e o ambiente de trabalho do intérprete. 


\section{Abstract}

Technology has been intimately related to Conference Interpreting since its birth as a recognized profession in the 30's. Since then, the interpretation booth proved to be the best solution in terms of work setting for the interpreters. During the evolution of this career up to now, many other technological solutions have been employed to help in the training of interpreters and their preparation for events. Currently there is a great variety of resources available to the interpreters, mainly due to the outstanding technological progress experienced in the last decades. Some of these resources are well known and used in this field, but many others are still unknown or underestimated. However, it is not enough for the interpreters just to know what is out there at their disposal and where to get it. In order to benefit as much as possible from the technology, interpreters should also understand why and how they should use this technology. Besides that, it is also possible to predict in which ways this rapid technological evolution will affect and change this career in the short and long run.

\section{Keywords}

Conference interpreting, technology and interpreting, technology and interpreter training, technology and event preparation, technology and interpreters' working environment. 


\section{Índice}

1 Apresentação

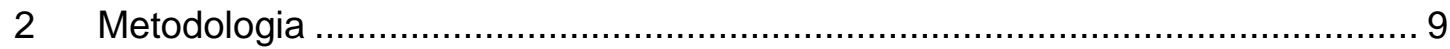

3 Soluções tecnológicas para a formação do intérprete ...................................... 13

3.1 Arquivos multimídia analógicos ou digitais ......................................... 13

3.2 Banco Multimídia (Multimedia Repository)............................................. 14

3.3 Computer Assisted Interpreter Training (CAIT) ................................... 16

3.4 Virtual Learning Environment (VLE) ................................................. 18

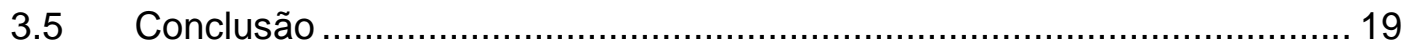

4 Soluções tecnológicas para a preparação de eventos ...................................... 20

4.1 Editores de Texto e Planilhas Eletrônicas................................................. 20

4.2 Dicionários e Enciclopédias Eletrônicos ………...................................... 21

4.3 Base de Dados Terminológica Online ...................................................... 24

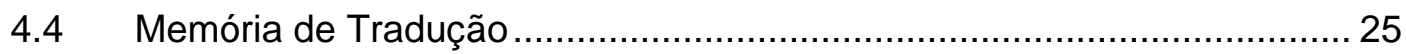

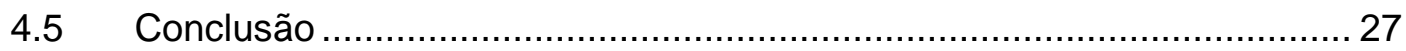

5 Soluções tecnológicas transformadoras do ambiente de trabalho .................... 28

5.1 Equipamento Portátil de Interpretação................................................... 29

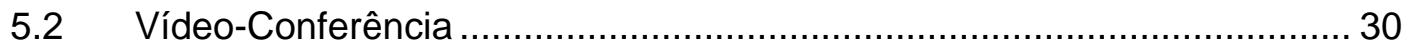

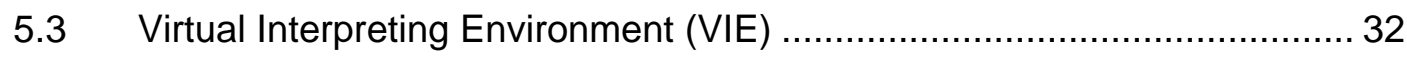

5.4 Sistemas de Reconhecimento da Fala .................................................. 34

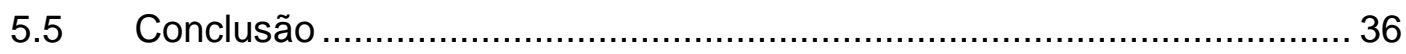

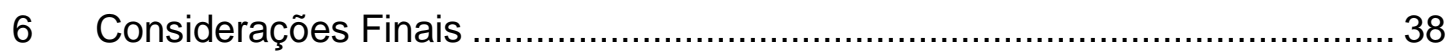




\section{Apresentação}

A proposta principal desta monografia é analisar como a tecnologia pode ser aplicada atualmente no trabalho dos intérpretes de conferências, o que nos levará inevitavelmente a observar como ela tem sido utilizada ao longo do tempo e como deverá influenciar esta profissão num futuro próximo. Ao tratar desta profissão num sentido amplo, a análise vai levar em consideração desde a fase de treinamento do intérprete, passando pela sua preparação para um evento em particular e chegando até o momento da interpretação em si. Desta forma, será possível avaliar todas as soluções tecnológicas que estão à disposição do intérprete, seja para ajudá-lo no seu desenvolvimento profissional, seja para lhe permitir um melhor desempenho ou maior flexibilidade na execução da interpretação.

Dois fatores foram determinantes na escolha do tema da monografia. $O$ primeiro e mais importante, é a constatação inequívoca de que nas últimas duas décadas observamos uma verdadeira revolução tecnológica que vem alterando a maneira como as pessoas vivem e trabalham. Em todas as áreas profissionais se pode notar uma influência cada vez mais significativa da tecnologia, mesmo naquelas consideradas mais imunes aos avanços tecnológicos. Email, smartphones, editores de texto e planilhas eletrônicas, entre vários outros, são exemplos de uma tecnologia que se tornou ubíqua no mercado de trabalho em geral $^{1}$. Mais especificamente em relação à interpretação de conferências, tratandose aqui de interpretação simultânea em cabine, o próprio ambiente de trabalho, como meio de veiculação do som recebido e emitido pelo intérprete, é uma construção tecnológica. Neste sentido, mais adiante será discutido inclusive como os recentes avanços tecnológicos vêm modificando e criando novas alternativas para este ambiente de trabalho. No entanto, o objetivo é ir muito além disso, de maneira que possamos identificar o maior número possível de soluções tecnológicas que são passíveis de serem utilizadas pelos intérpretes, trazendo-lhes diferentes benefícios.

\footnotetext{
${ }^{1}$ A grande maioria das soluções apresentadas neste trabalho pertencem ao domínio da Tecnologia da Informação (TI), que se refere ao armazenamento, processamento e transmissão da informação através de computadores e redes de telecomunicação. No entanto, neste trabalho será utilizado o termo "tecnologia" no seu sentido mais amplo, pois serão consideradas também algumas soluções que não se inserem na TI, como a cabine de interpretação, por exemplo.
} 
O segundo fator que motivou a escolha deste tema é o fato do autor desta monografia ter muitos anos de experiência profissional no mercado da Tecnologia da Informação (TI). A natural familiaridade com o assunto é uma vantagem clara, pois the permite analisar melhor a evolução histórica e intuir os próximos passos no mundo da TI. Por outro lado, esta familiaridade pode representar igualmente uma armadilha, pois é sabido que quanto mais nos sentimos conhecedores de um assunto, mais temos tendência a discorrer sobre ele de maneira informal e unilateral. Há assim um risco de se reduzir o discurso a uma opinião pessoal que não se encontra fundamentada no rigor investigativo que um estudo de caráter acadêmico requer. Desta forma, as análises e conclusões apresentadas neste trabalho serão devidamente desenvolvidas no arcabouço de uma metodologia empírica que será explicada em seguida. 


\section{Metodologia}

Quando falamos em tecnologia num sentido amplo, geralmente falamos de soluções, ferramentas e recursos tecnológicos como se fossem expressões análogas e intercambiáveis. No entanto, como no contexto acadêmico se requer mais atenção e precisão no que se refere à nomenclatura, é necessário estabelecer a distinção entre estes termos aparentemente idênticos, pelo menos na maneira como serão utilizados neste trabalho: as soluções tecnológicas, de um lado, são compreendidas aqui como tipos genéricos e abstratos; as ferramentas ou recursos tecnológicos, por outro lado, são produtos de mercado, concretos e específicos. Poderíamos ir além e estabelecer ainda uma diferenciação entre ferramentas e recursos, mas isso não é relevante para o desenvolvimento desta análise e poderia gerar mais confusão do que esclarecimento. Logo, no contexto atual, podemos determinar que ferramentas e recursos serão empregados aqui como termos análogos e intercambiáveis.

O mais importante é definir claramente que a abordagem analítica deste trabalho será feita em relação às soluções tecnológicas (logo, uma abordagem generalista), e não em relação às ferramentas tecnológicas em particular. Uma solução pode ser representada por mais de uma ferramenta, e quando há muita demanda de mercado, geralmente existem dezenas delas. Para citar um caso familiar, podemos falar dos processadores de texto, que são na verdade uma única solução tecnológica, onde se inserem várias ferramentas específicas, como, por exemplo, o MS Word (da Microsoft), o WordPerfect (da Corel) e o iWork (da Apple). É evidente que existirá uma diferença não apenas de qualidade, mas igualmente de funcionalidades em cada ferramenta. No entanto, há certamente um conjunto de funcionalidades básicas (core features) que não podem faltar, pois compõem a essência da solução tecnológica que se oferece.

Ao trabalharmos com soluções, no lugar de ferramentas, observamos algumas vantagens. Primeiramente, não faremos escolhas em relação a um ou outro fabricante, evitando assim comparações entre produtos similares (não entraremos na polêmica Apple versus Microsoft, por exemplo). Outra vantagem é que não estaremos tão dependentes do momento histórico atual em relação ao desenvolvimento tecnológico. Neste mercado, assim como em qualquer outro, as 
ferramentas nascem, envelhecem e finalmente morrem, sendo substituídas por versões mais avançadas ou produtos de concorrentes que tenham se mostrado mais atentos às necessidades dos usuários. A solução tecnológica é, por outro lado, muito mais duradoura (claro, sempre quando for uma solução que atenda a uma necessidade do mercado). Seguindo o exemplo dos processadores de texto, é impressionante como evoluíram nos últimos 20 anos (basta lembrar-nos dos primeiros que se tornaram populares para ambiente $\mathrm{DOS}^{2}$, com suas telas de fundo pretas, funcionalidades limitadas e comandos de teclado). Desde então, centenas de produtos foram lançados, apresentando avanços significativos um após o outro, mas todos são ainda conhecidos como processadores de texto.

É evidente que nesta análise não podemos almejar uma completa independência em relação ao momento histórico em que vivemos. Algumas soluções só se materializam em ferramentas quando a tecnologia atinge um grau de maturidade que permita o seu desenvolvimento. Um exemplo recente é o aparecimento dos tablets, que surgiram com o primeiro iPad, da Apple, e hoje invadiram o mercado com o lançamento de novas versões e modelos similares de diversos concorrentes. Mas sem que a fabricação de componentes de computadores tivesse alcançado tal grau de miniaturização, os tablets não poderiam existir. Tendo isso em mente, este estudo não ficará necessariamente limitado às soluções tecnológicas que se apresentam atualmente no mercado como devidamente amadurecidas, mas também tentará visualizar aquelas que mostram um potencial de desenvolvimento futuro, com um impacto relevante no trabalho do intérprete.

Isso não quer dizer, no entanto, que as ferramentas tecnológicas serão ignoradas neste estudo. Seria muito difícil e pouco esclarecedor, principalmente tratando-se de tecnologia, onde tudo é prático e objetivo, tentar desenvolver uma análise puramente conceitual. As ferramentas naturalmente serão mencionadas e utilizadas amplamente como exemplos de aplicação prática de uma solução tecnológica. Não obstante, não se pretende aqui elaborar uma lista exaustiva de todas as ferramentas disponíveis no mercado para uma determinada solução, ou mesmo apresentar aquela que seja aparentemente a mais correta para o uso por

\footnotetext{
${ }^{2}$ O DOS foi um dos primeiros sistemas operacionais criados para computadores pessoais, que se tornou muito popular na década de 80 .
} 
parte dos intérpretes. Naturalmente, os exemplos serão escolhidos em função da popularidade e das funcionalidades apresentadas pelas ferramentas, buscando se manter o mais próximo da realidade quanto possível. Porém, o objetivo não é mostrar uma receita completa do que o intérprete pode ou deve utilizar no seu trabalho. Ainda que muitos intérpretes utilizem uma ferramenta $X$, mas o exemplo empregado no estudo se refira à ferramenta $Y$, sendo que ambas se tratem da mesma solução tecnológica, a análise permanecerá igualmente válida.

Para se trabalhar com uma metodologia consistente e útil, devemos inicialmente determinar também uma tipologia das soluções. A tipologia é uma organização teórica dos objetos de estudo. Ela consiste na identificação de algumas poucas categorias conceituais que agruparão as diversas soluções a serem estudadas, facilitando assim tanto a análise como a apresentação das mesmas. Sendo um exercício de classificação mais ou menos deixado ao livre-abítrio do autor do estudo acadêmico, dificilmente pode-se falar que uma tipologia esteja certa ou errada. No entanto, trata-se de uma atividade crítica, porque uma escolha bem feita na elaboração de uma tipologia pode facilitar sobremaneira o desenvolvimento analítico do trabalho e influenciar inclusive na sua conclusão.

A tipologia que se mostrou mais ajustada aos objetivos deste trabalho é aquela baseada no propósito de uso da solução tecnológica. Portanto, ao dizermos que uma solução pertence a uma determinada categoria ou tipo, estaremos respondendo a uma questão muito simples: "qual é a utilidade desta solução para o intérprete?" Com isso em mente, expõe-se abaixo cada um dos tipos que serão analisados e uma breve descrição de cada um.

1. Soluções tecnológicas para a formação do intérprete: incluem todas as ferramentas e recursos empregados na formação inicial e continuada do intérprete, objetivando a aquisição e a prática de habilidades linguísticas específicas para o trabalho de interpretação;

2. Soluções tecnológicas para a preparação de eventos: incluem todas as ferramentas e recursos que podem ser empregados na preparação para o exercício da interpretação em um evento específico, que em geral irá envolver trabalho de pesquisa e criação de um glossário, entre outros. 
3. Soluções tecnológicas transformadoras do ambiente de trabalho: incluem todas as ferramentas e recursos que têm um potencial de transformar e flexibilizar o ambiente de trabalho, permitindo, por exemplo, a criação de ambientes virtuais e remotos através de video-conferência.

Antes de prosseguir com a análise detalhada de cada uma destas categorias, convém esclarecer que as soluções incluídas em cada uma deverão representar uma vantagem ou ganho específicos para o intéprete em função da categoria onde se inserem. As soluções que sejam consideradas extremamente genéricas, cuja polivalência não nos permita associá-las preferencialmente a uma categoria em detrimento de outras, ou que sejam de uso amplo e irrestrito a qualquer área profissional, por mais que sejam igualmente de grande utilidade para a maioria dos intérpretes, não serão consideradas no escopo deste trabalho. São exemplos disso soluções como ferramentas de busca ${ }^{3}$ (cuja expressão mais popular hoje é o Google) e e-mail. É notório que a grande maioria dos intérpretes, senão todos, já incorporou tais soluções na sua rotina profissional, certamente obtendo inúmeros benefícios. No entanto, este estudo busca incluir apenas aquelas soluções às quais se pode atribuir uma utilização específica para a área da interpretação.

Cabe igualmente ressaltar que, ao longo deste trabalho, no momento de se representar uma solução tecnológica com um ou mais exemplos de ferramenta ou recurso, sempre quando não houver diferenças significativas de qualidade, se dará preferência aos que estejam disponíveis online, na internet, e sejam de uso gratuito. Um exemplo são os dicionários eletrônicos, cujas versões gratuitas online cumprem a função desejada, ainda que as versões comercializadas em cd-rom apresentem outras funcionalidades mais avançadas. Assim sendo, este trabalho também poderá servir como uma referência de ferramentas de fácil acessibilidade para estudantes e profissionais da interpretação.

\footnotetext{
3 "Search engines", em inglês
} 


\section{Soluções tecnológicas para a formação do intérprete}

Nesta categoria encontraremos as ferramentas e recursos empregados tanto na formação inicial do intérprete, em curso acadêmico regular, assim como no treinamento pós-formação, seja ele realizado em cursos específicos ou de maneira autônoma. O objetivo da ferramenta é auxiliar a aquisição e a prática de habilidades linguísticas específicas para o trabalho de interpretação. Se fôssemos considerar igualmente as ferramentas disponíveis para a aquisição de habilidades linguísticas genéricas (por exemplo, para se aprender uma nova língua ou praticar a pronúncia de palavras), o universo contemplado seria em muito aumentado e o escopo deste estudo se tornaria mais difuso. Serão analisados a seguir as ferramentas e recursos incluídos no estudo.

\subsection{Arquivos multimídia analógicos ou digitais}

Os arquivos multimídia são os recursos mais amplamente utilizados no treinamento de intépretes, e podem conter tanto áudio como vídeo, dependendo do tipo de mídia e formato do arquivo. A mídia é a tecnologia de armazenamento e reprodução dos arquivos, podendo ser classificada como analógica ou digital. Exemplos de mídia analógica são as fitas cassette e as fitas de rolo. Este tipo de mídia, no entanto, cai cada vez mais em desuso devido ao aparecimento de diversos aparelhos de mídia digital que são baratos e de manuseio mais fácil, assim como de maior portabilidade e durabilidade. Atualmente a lista de formatos de arquivo para mídia digital é muito longa, mas entre os mais populares estão o $\mathrm{mp} 3 \mathrm{e}$ o wav, para áudio, assim como o avi e o wmv, para vídeo. Entre os aparelhos, há desde os discos rígidos $(H D)$, que se encontram embutidos nos computadores (mesmo nos tablets), até os pequenos e portáteis pen drives USB.
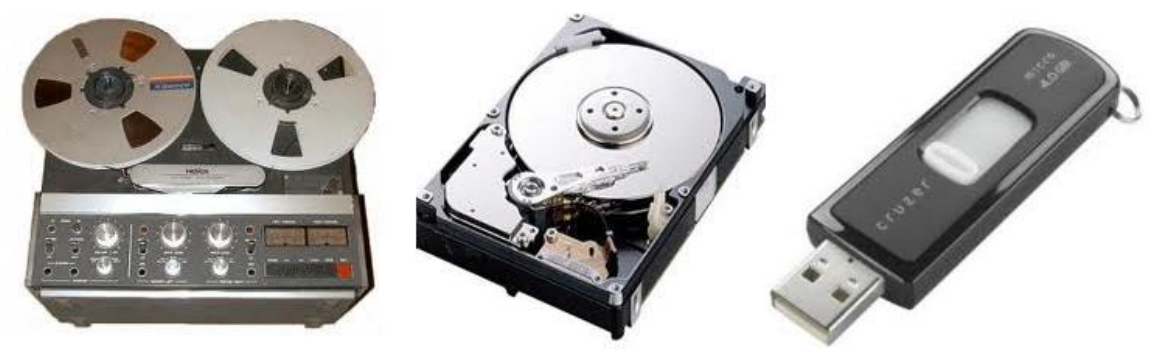

Figura 1: Exemplos de mídia analógica (fita de rolo) e de mídia digital (disco rígido e pen drive) 
Atualmente temos também um número quase infinito de arquivos de áudio e de vídeo disponíveis na internet. Naturalmente, eles também se encontram armazenados em mídia digital, em servidores interconectados ao redor do mundo. Mas é a diversidade de conteúdo, a ubiquidade (com um simples acesso à internet, a mídia física torna-se desnecessária) e o custo zero, que fazem deste acervo uma oportunidade única para a utilização no treinamento dos intérpretes de hoje. São programas de TV e de rádio, entrevistas, discursos, palestras e muito mais. São chamadas de podcasts quando se tratam de gravações de áudio ou vídeo realizadas com periodicidade para serem publicadas na internet. Além disso, há websites que foram criados com a finalidade específica de armazenar tais arquivos e prover uma ferramenta de busca para que o usuário consiga localizar o arquivo desejado com o uso de palavras-chave e categorias, entre outros. Como exemplos, podemos citar o popular YouTube, para qualquer tipo de vídeo, e o TedTalks, que oferece talvez um conteúdo mais apropriado para intérpretes, com inúmeras palestras tratando de assuntos diversos.

\subsection{Banco Multimídia (Multimedia Repository)}

Os bancos multimídia (conhecidos também pelo nome em inglês, multimedia repositories), representam um passo além do simples armazenamento de arquivos multimídia, como mencionado no item anterior. São projetos de envergadura desenvolvidos pela iniciativa do meio acadêmico, de instituições governamentais ou mesmo de grandes empresas, com o objetivo de reunir em um único corpus ${ }^{4}$ um vasto material para pesquisa. O foco aqui não é simplesmente a capacidade de armazenar o maior volume possível de material, mas também de conseguir recuperá-lo a partir de pesquisas detalhadas relativas ao seu conteúdo, uma funcionalidade avançada que os "repositórios públicos", como o YouTube e o TedTalks, não dispõem. No Brasil, certamente um dos maiores bancos do gênero é o CEDOC $^{5}$, da TV Globo. Além do histórico de imagens, há também todo um trabalho paralelo de documentação, que pode incluir atividades como a criação de uma ficha técnica, transcrição de aúdio, legendagem, associação múltipla e cruzada com termos e outras imagens, etc.

\footnotetext{
${ }^{4} \mathrm{O}$ Corpus linguístico é um conjunto de textos escritos ou falados numa língua que serve como base de análise.

${ }^{5}$ Trata-se, no entanto, de um banco de dados privado, que não está acessível ao público em geral.
} 
No caso específico da interpretação de conferências, que aqui nos interessa, temos iniciativas como o Speech Repository da Direção Geral de Interpretação da União Européia (também conhecido como DG SCIC) ${ }^{6}$. No portal online deste projeto encontramos um excelente resumo do seu objetivo:

"O Speech Repository é um sistema online de treinamento para estudantes de interpretação de conferências. Ele fornece aos estudantes gravações de vídeo de alta qualidade de situações reais, como reuniões da UE, por exemplo. Os estudantes têm acesso a uma grande variedade de discursos que poderão ver e usar para praticar a interpretação de conferências." 7 (Minha tradução, Speech Repository project, 2012)

O material, que consiste de gravações de conferências públicas, coletivas de imprensa, debates parlamentares e entrevistas, foi classificado por língua e sotaque, nível de dificuldade, assunto e até quanto à utilização pretendida (interpretação simultânea ou consecutiva). Isso permite ao usuário fazer uma busca usando como filtro cada um destes parâmetros.

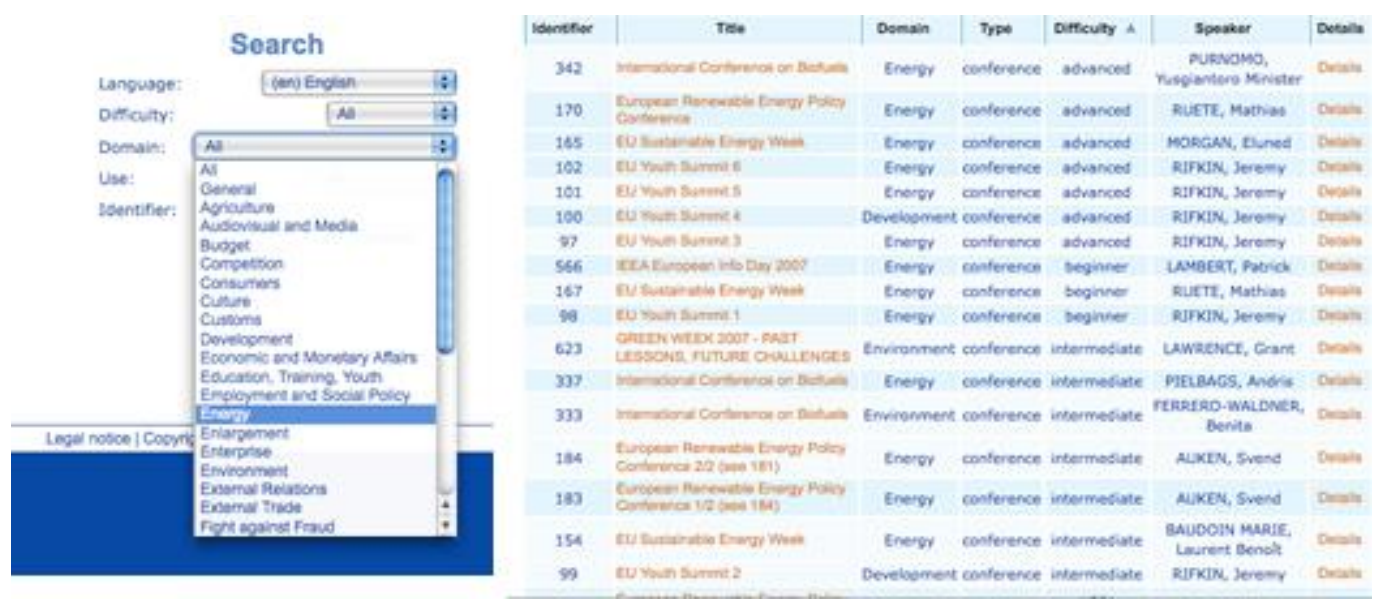

Figura 2: Interface gráfica do Speech Repository, que permite busca de conteúdo através de diversos parâmetros.

Em um ensaio sobre o desenvolvimento de uma ferramenta similar, o EPIC (European Parliament Interpreting Corpus), seus autores comentam a dificuldade de

\footnotetext{
${ }^{6}$ Infelizmente, o acesso está restrito a instituições e universidades européias.

7 "The Speech Repository is an online learning system for students of conference interpreting. It provides students with high-quality video recordings from real-life situations such as EU meetings. Students have access to a wide range of speech content that they can view and use to practice interpreting."
} 
se realizar tal projeto (BENDAZZOLI e SANDRELLI, 2005). O maior desafio, no entanto, foi o processo de transcrição, que teve de ser realizado a partir do zero em todo o material recolhido, utilizando-se ferramentas de reconhecimento da fala. Tais ferramentas, por sua vez, podem ter outro papel e ser também utilizadas para outra finalidade mais específica para os intérpretes, e assim sendo serão discutidas com mais detalhes oportunamente em outro tópico.

\subsection{Computer Assisted Interpreter Training (CAIT)}

Ferramentas CAIT são programas desenvolvidos com o propósito específico de auxiliar os professores de interpretação na preparação de exercícios. Os alunos, por outro lado, utilizarão este mesmo software para realizar os exercícios. Neste sentido, trata-se de uma plataforma de imersão profissional, onde a maior parte do trabalho interativo entre professor e aluno pode ocorrer, principalmente devido ao fato de que o estudo da interpretação consiste mais de aulas práticas do que de aulas teóricas.

Na sua tese de doutorado sobre o uso das Tecnologias da Informação na interpretação de conferências, Diana Cristina Berber-Irabien (2010) cita o Black Box como uma das ferramentas mais completas de CAIT disponíveis no mercado, permitindo a criação de exercícios em todos os modos de interpretação, inclusive com exercícios de sight translation ${ }^{8}$. Por outro lado, sendo uma ferramenta standalone, os alunos podem igualmente realizar os exercícios a qualquer momento, sem a supervisão direta de um professor. Eles poderão, utilizando funcionalidades da ferramenta baseadas na comparação entre o original e a interpretação, avaliar criteriosamente diferentes aspectos do seu próprio desempenho, incluindo o time lag ou décalage, e a frequência vocal (onde o aluno pode verificar se há diferenças de prosódia entre as duas gravações).

Em outro ensaio, dedicado exclusivamente à análise do Black Box, a autora Annalisa Sandrelli (2005) descreve detalhadamente suas funcionalidades. Entre as várias vantagens do uso de uma ferramenta como tal, ela observa a facilidade de se criar conteúdo com arquivos de mídia e de texto, incluindo recursos didáticos adicionais, como por exemplo exercícios escritos e uma versão da intepretação

\footnotetext{
8 O Sight translation acontece quando o intérprete recorre a um texto escrito para realizar a interpretação, geralmente para acompanhar um orador que esteja lendo a sua palestra.
} 
realizada pelo próprio professor. Todos estes recursos podem então ser organizados em módulos. A autora afirma também que a criação de material didático que pode ser empregado na prática autônoma dos alunos constitui uma maneira eficiente de se incentivar a auto-avaliação, claro, sempre quando bem orientada previamente por um professor.

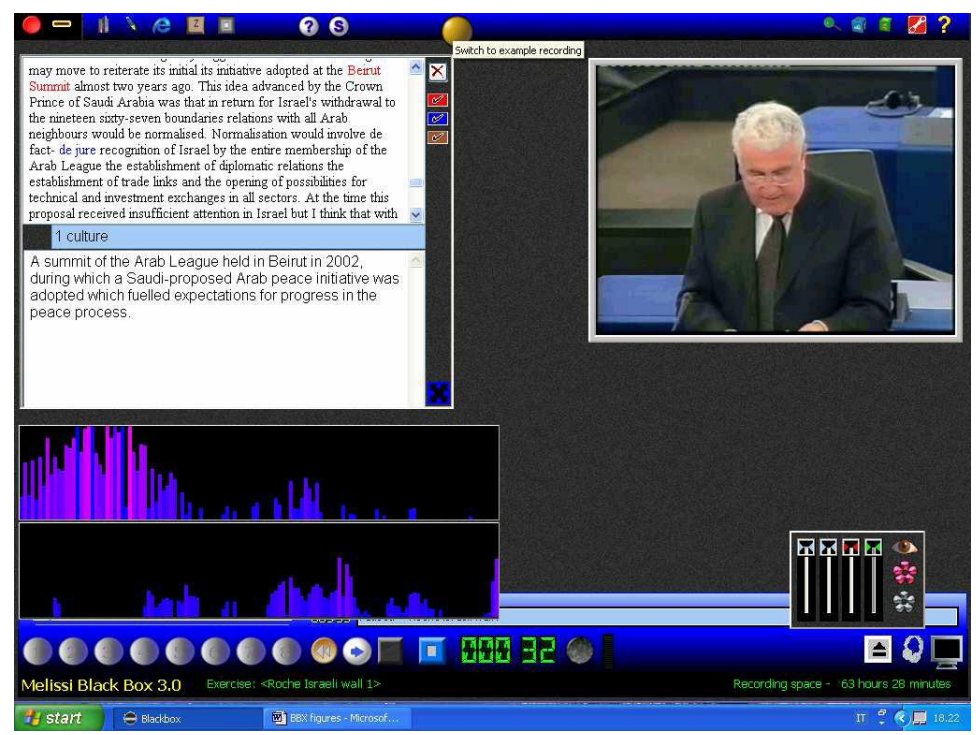

Figura 3: A interface do Black Box, onde nota-se o vídeo, a transcrição e as frequências vocais do orador e do aluno sendo apresentados paralelamente.

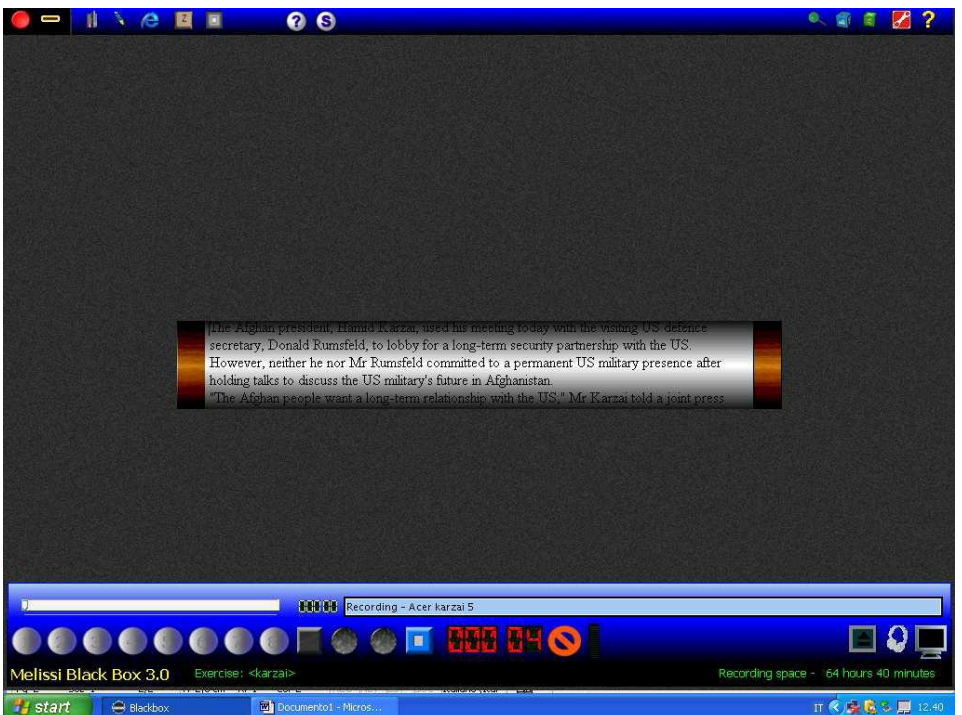

Figura 4: Um exercício de sight-translation usando texto rolante no Black Box. 


\subsection{Virtual Learning Environment (VLE)}

As ferramentas de VLE, no contexto deste estudo, são aquelas que, apesar de terem sido criadas como plataformas mais ou menos genéricas de ensino a distância, apresentam certas funcionalidades específicas que as fazem candidatas para o emprego no ensino da interpretação. Tais ferramentas são projetadas para funcionar usando a internet como veículo de transmissão de dados, criando um espaço exclusivo que emula um ambiente de ensino onde o professor e seus alunos compartilham recursos comuns apesar de se encontrarem fisicamente distantes.

O Melissi Digital Language Lab (MDLL), criado pela mesma empresa que desenvolveu o já mencionado Black Box, é hoje talvez o melhor representante deste tipo de ferramenta no mercado. O MDLL reúne todas as funcionalidades esperadas de uma ferramenta VLE versátil, como por exemplo a criação de sessões com até 40 alunos, o armazenamento e a distribuição de arquivos de texto e multimídia, a disponibilização de canais de chat e voz para a comunicação entre os participantes, a possibilidade do professor visualizar as telas dos alunos e ainda controlar os seus mouses e teclados, quando necessário (Melissi Version 4 Key Features, 2012). No entanto, além dos avançados recursos de multimídia, o MDLL se mostra bem adequado para o ensino da interpretação porque possui um plug-in que the confere a capacidade de simular, com muito realismo, sessões de conferência. Este programa opcional, comercializado à parte, é chamado de Virtual Interpreting Suite (VIS) e permite a emulação de múltiplos canais de voz usando a tecnologia VoIP (Voice over IP). Podemos notar nos exemplos fornecidos abaixo (minha tradução, Melissi Virtual Interpreting Suite, 2012), retirados do próprio website da ferramenta, que as situações simuladas são potencialmente muito variadas:

- "O professor (ou convidado) é o orador principal no canal 1. Um aluno interpreta no canal 2. Outro aluno pode ouvir os dois discursos, original e interpretado, em tempo real. ${ }^{9}$

- Como acima descrito, porém outras línguas são interpretadas nos canais 3, 4, 5, etc. Os ouvintes podem escolher qual canal querem ouvir. ${ }^{10}$

\footnotetext{
${ }^{9}$ Tutor (or guest) is main speaker on channel 1. Student on channel 2 interprets. Other students can listen to the source and target in real time.

${ }^{10}$ As above, but other target languages are interpreted on channels 3, 4, 5, etc. Listeners can select their listening channels.
} 
- O orador A é grego. O intérprete B interpreta para o alemão. O intérprete C, para o holandês. Os ouvintes podem escolher a sua língua. ${ }^{11}$

- Até seis oradores estão participando de um seminário. $O$ intérprete $X$ pode monitorar o seminário e interpretar para uma língua-destino."12

\subsection{Conclusão}

É importante observar que as soluções tecnológicas apresentadas aqui não representam estágios evolutivos, mas também não devem ser consideradas como peças desconectadas entre si. Na verdade, são opções que podem ser vistas como complementares. Certamente, também se mostrarão ainda mais interessantes e úteis se forem combinadas e incorporadas a um programa educacional consistente.

A London Metropolitan University talvez seja um bom exemplo neste sentido. Ela oferece um curso de pós-graduação em interpretação de conferências em que são colocados à disposição do aluno equipamentos digitais com funcionalidades multimídia, um acesso ao Speech Repository do DG SCIC, assim como um Virtual Learning Environment para aulas virtuais e acesso remoto de recursos (MA Conference Interpreting, 2012). Ainda que não seja o propósito deste estudo quantificar atualmente no mercado a utilização das soluções tecnológicas na formação do intérprete, é interessante verificar que já há instituições que estão fazendo pleno uso destas soluções e, assim sendo, não se trata apenas de um potencial que um dia quiçá venha a se materializar.

\footnotetext{
${ }^{11}$ Speaker A is Greek. Interpreter B interprets into German. Interpreter C interprets into Dutch. Listeners can select their language.

${ }^{12} \mathrm{Up}$ to six speakers are conducting a seminar. Interpreter X can monitor the seminar and interpret into a target language.
} 


\section{Soluções tecnológicas para a preparação de eventos}

Nesta categoria encontramos todas as ferramentas e recursos utilizados pelos intérpretes durante a preparação para um evento. Sabemos que, ainda que os intérpretes sejam exímios conhecedores da língua a ser interpretada e portadores de um vasto conhecimento sobre diversos domínios, o exercício da interpretação presume uma etapa de preparação que antecede os eventos. Esta etapa consiste em um meticuloso trabalho de levantamento, pesquisa e memorização dos termos que certa ou provavelmente surgirão no decorrer dos eventos. Neste processo, o intérprete então geralmente cria um glossário próprio, expande algum que já possua (criado previamente para outro evento similar, por exemplo), ou pode ainda elaborar um que tenha recebido de um colega.

\subsection{Editores de Texto e Planilhas Eletrônicas}

Editores de texto, como o MS Word, e planilhas eletrônicas, como o MS Excel, são altamente populares e utilizados para os mais variados objetivos. Há no mercado uma grande oferta deste tipo de ferramenta, levando-se em conta os diversos sistemas operacionais disponíveis (Windows, Mac, Linux, etc.). O produto pode ser gratuito e oferecido diretamente a partir da internet (freeware), pode estar "empacotado" com o sistema operacional adquirido (bundled software), ou pode ser ainda oferecido em lojas ou departamentos de informática (off-the-shelf), sejam reais ou virtuais.

Para o intérprete, no entanto, estas ferramentas oferecem uma facilidade bem específica: criar, editar e imprimir glossários de maneira rápida, assim como facilitar o compartilhamento com colegas, devido à extrema popularização dos formatos de arquivos. O glossário é simplesmente uma tabela que possui duas ou mais colunas, dependendo do número de línguas usadas. Na primeira coluna se coloca a lista de termos e expressões a serem pesquisados e quiçá traduzidos, para que as colunas seguintes sejam então preenchidas com as respectivas traduções. Tais ferramentas oferecem também diversas funcionalidades de formatação para o usuário, fazendo com que ele possa, entre várias outras opções, escolher as cores, fontes e formatos de tabela que melhor lhe convém, permitindo assim um alto grau de personalização do glossário. 
Uma ferramenta que representa um passo adiante nesse tipo de solução, tendo sido projetada principalmente para uso em cabine, durante a interpretação, é o Interplex ${ }^{13}$. A sua interface é muito similar a uma planilha Excel, porém com funcionalidades que a fazem mais apropriada para a criação e manipulação de glossários multilíngües. A vantagem principal, no entanto, é a busca de termos e expressões, que já está pensada para um acesso mais imediato e rápido, podendo ser executada em vários glossários ao mesmo tempo. O objetivo é, naturalmente, minimizar o impacto causado no desempenho do intérprete, uma vez que ele estaria realizando outra tarefa em paralelo. A ferramenta também permite a importação e a exportação de glossários em formato Excel e Word.

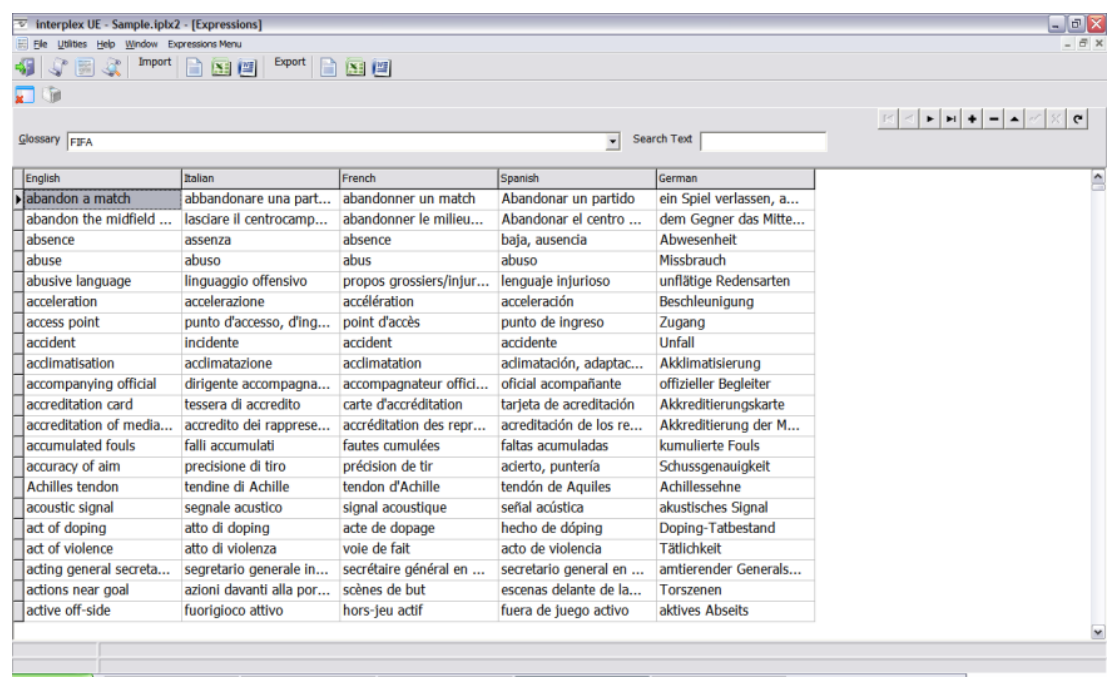

Figura 5: O Interplex: glossários multilíngües e uma busca fácil e rápida.

\subsection{Dicionários e Enciclopédias Eletrônicos}

Se, por um lado, editores de texto e planilhas cumprem bem a função de ferramentas para confeccionar glossários, por outro lado, dicionários e enciclopédias eletrônicos são recursos muito explorados na hora de se realizar a pesquisa de termos, expressões, nomes próprios, enfim, tudo aquilo que for necessário para uma boa preparação para o evento. Neste sentido, geralmente são utilizados de maneira complementar pelo intérprete.

\footnotetext{
${ }^{13}$ Uma versão demo está disponível no website da ferramenta (veja o endereço no Índice Remissivo).
} 
Dicionários eletrônicos são, muitas vezes, versões eletrônicas de dicionários que já existem em papel (como o Merriam-Webster, por exemplo). No entanto, na versão eletrônica geralmente encontramos funcionalidades adicionais que a versão em papel não poderia jamais realizar. Algumas destas funcionalidades são muito úteis para o intérprete como, por exemplo, a possibilidade de se executar arquivos de áudio que mostram a pronúncia correta dos termos, incluindo às vezes opções de pronúncias diferentes em função da localização geográfica (diferenças entre o sotaque inglês e o americano, por exemplo). Os dicionários eletrônicos podem ser comercializados em diferentes mídias (em $C D-R O M$, por exemplo), porém os mais populares certamente são aqueles disponíveis na internet, chamados de dicionários online, devido à facilidade de acesso e à gratuidade. Alguns dicionários seguem um modelo de negócio em que uma versão mais básica é oferecida gratuitamente na internet, mas se o usuário quiser acesso a mais conteúdo ou a funcionalidades mais avançadas deverá pagar por isso.

Os dicionários eletrônicos podem ser mono, bi ou multilíngües, cada tipo podendo ser utilizado para fins específicos pelo intérprete. Por exemplo, o intérprete pode já conhecer a tradução de uma palavra, mas se quiser entender melhor a sua definição ou mesmo conhecer opções de sinônimos e antônimos, provavelmente o dicionário monolíngüe Ihe será mais útil. Os dicionários bi ou multilíngües, por outro lado, são mais apropriados para se buscar a tradução de um termo, ou opções de tradução. Um exemplo de dicionário multilíngüe, que talvez seja também um dos dicionários mais abrangentes na internet atualmente, é o WordReference.com. Além de outras funcionalidades já mencionadas, comuns a outros dicionários online, ele apresenta, na página do termo pesquisado, links para fóruns de discussão onde usuários publicam perguntas e respostas sobre o termo em questão. Os fóruns são aparentemente freqüentados por tradutores, sejam profissionais ou não, pois muitas das perguntas são relativas a dúvidas sobre a tradução mais apropriada do termo, dado um contexto ou uma frase.

As enciclopédias têm um histórico similar, pois nasceram há muito tempo e também estão encontrando na mídia digital um veículo propício para a publicação, atualização e difusão do seu conteúdo. A Encyclopaedia Britannica, um modelo em termos de tradição e confiabilidade, anunciou em março de 2012 que, depois de 250 anos, vai deixar de produzir a versão impressa, composta por 32 volumes (CNN 
Money, 2012). Apesar de já oferecer versões em CD/DVD-ROM, a Encyclopaedia Britannica vai concentrar seus esforços na versão online. Como podemos observar, a tendência é que cada vez mais dicionários e enciclopédias, assim como livros e outras obras impressas, continuem migrando para a internet. Atualmente inclusive já se debate na sociedade se isso levará ao "fim do livro", entendido como obra impressa em papel.

Há em particular uma enciclopédia que já nasceu expressando o espírito dos novos tempos, a Wikipedia. Ela existe somente na internet, o acesso é gratuito e o seu conteúdo é criado totalmente por usuários, algo que está bem evidente no seu próprio lema: "a enciclopédia livre que todos podem editar" (Wikipédia, 2012). O processo de criação e evolução dos artigos é bem dinâmico, permitindo que qualquer pessoa possa criticá-los (recomendando a inclusão de referências, por exemplo) e até mesmo corrigi-los, contribuindo assim para uma melhoria contínua do conteúdo (Wikipedia, 2012). Ainda que não exista uma organização central que coordene, avalie e autorize a publicação de artigos, o meio acadêmico tem um papel muito importante na Wikipedia, seja responsabilizando-se por artigos específicos ou participando de projetos para a edição de muitos deles.

$\mathrm{Na}$ interpretação, assim como no meio acadêmico em geral, se discute se a Wikipedia é uma fonte válida de informações. A questão se torna sensível no caso dos intérpretes, que no papel de transmissores das informações veiculadas entre especialistas de uma área, devem buscar sempre obter informações confiáveis e precisas de fontes que sejam autoridades reconhecidas no assunto. No entanto, ainda que não seja considerada como a palavra final sobre um tema qualquer, a Wikipedia pode ser utilizada como um recurso valioso em algumas situações. Há pelo menos dois exemplos neste sentido. Primeiro, se o intérprete estiver buscando informações básicas sobre um assunto que já desfrute de certa popularidade, aumentando assim as chances de que, caso houvesse discordâncias sobre parte do conteúdo, outras pessoas já o teriam criticado e corrigido. Neste caso, o intérprete não está preocupado em aprofundar o seu conhecimento, utilizando assim o recurso apenas como uma referência inicial. O segundo exemplo refere-se a um simples aumento do seu conhecimento contextual, quando o intérprete almeja apenas ampliar o seu conhecimento sobre um determinado aspecto do assunto em questão, sabendo que ele não será o foco de discussão do evento. 


\subsection{Base de Dados Terminológica Online}

Uma ampla base de dados de terminologias disponível na internet pode ser considerada, certamente, um dos recursos mais úteis na preparação de um evento, principalmente se o intérprete não puder contar com o apoio de algum especialista da área em questão. O diferencial, em relação a um dicionário técnico qualquer, é que a base de dados é multilíngüe, encontra-se sempre atualizada (considerando que, sendo de acesso público na internet, há uma organização que se ocupe disso) e abrange domínios variados, contextualizando assim os resultados mostrados em função da área ou setor onde se aplica.

Talvez o exemplo mais completo atualmente deste tipo de base de dados seja o IATE (InterActive Terminology for Europe). Este projeto foi iniciado em 1999, incorporando todas as bases de dados de terminologia existentes para os serviços de tradução da União Européia, e conta hoje com aproximadamente 1,4 milhões de termos multilíngües, incluindo abreviaturas. $\mathrm{O}$ objetivo é fornecer uma infra-estrutura online comum para a UE, aumentando assim a disponibilidade e a padronização das terminologias utilizadas. Entre as várias instituições européias que são parceiras deste projeto, encontram-se o Parlamento, o Tribunal de Justiça e o Banco Central Europeu (IATE, 2012).

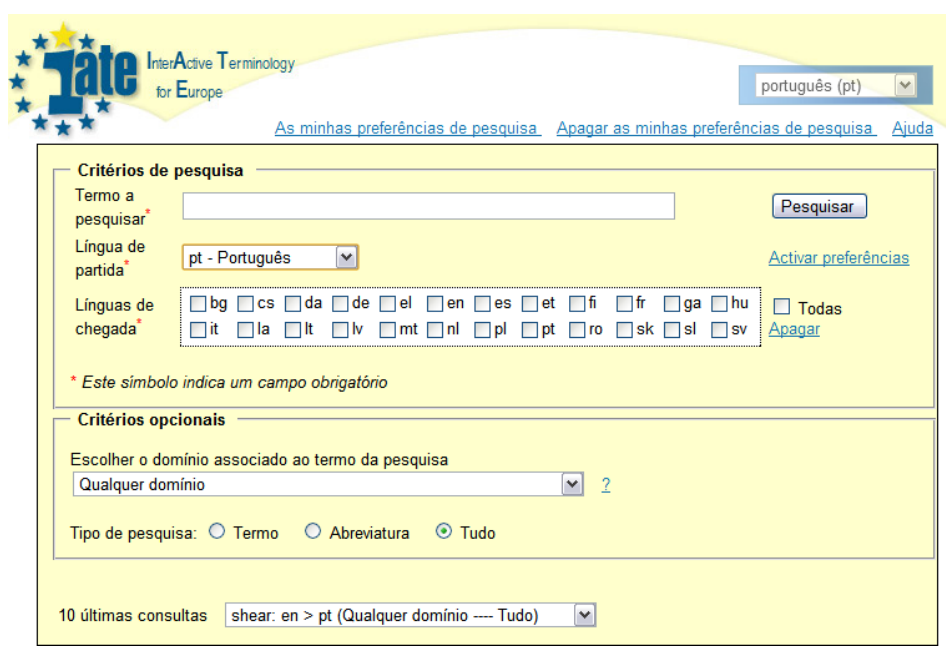

Figura 6: A página web do IATE apresenta uma interface simples e intuitiva.

Apesar de o IATE mostrar uma interface simples, os resultados deixam claro que há um universo de informação que pode ser explorado com esta ferramenta. 
Por exemplo, observamos uma enorme diferença de resultados ao se pesquisar o termo "shear" no WordReference.com, que nos retornou quatro resultados possíveis em português, e no IATE, que nos retornou 142 resultados (naturalmente, não foi selecionado nenhum domínio em particular para a pesquisa, justamente para que aparecessem todos os resultados possíveis):

\section{$\underline{\text { WordReference.com }}$}

1) shear: tosquiar, tosar;

2) shear off: ir-se, desaparecer

IATE (por economia de espaço, mostram-se os resultados parciais de 5 domínios)

1) shear: cisalhamento (metalurgia e siderurgia)

2) sheep shear: tosquiadeira (agricultura, silvicultura e pesca)

3) shear pin safety: cavilha de segurança (construção civil)

4) shear action: ação cortante (composto químico)

5) shear wave: onda rotacional (ciências da terra)

Naturalmente, esta diferença significativa de resultados não se deve a uma diferença na qualidade das ferramentas, até porque já se mencionou anteriormente o WordReference.com como um dicionário online robusto, mas para uma linguagem mais coloquial. No entanto, neste caso, propositalmente o termo escolhido possui um caráter extremamente técnico, usado em diversas áreas ou domínios, para que assim possamos evidenciar as diferenças na utilização de ambas as ferramentas. É interessante observar também como os resultados do IATE podem ser tão distintos uns dos outros, não havendo duas traduções sequer nos exemplos mostrados que se assemelhem, pelo simples fato de que pertencem a domínios diferentes.

\subsection{Memória de Tradução}

As Memórias de Tradução (também conhecidas como TM, de Translation Memory) são ferramentas que dispõem de uma ampla base de dados de segmentos de textos já traduzidos, de fontes diversas. Estes segmentos podem ser parágrafos, frases, expressões, etc. A ferramenta pode ser multilíngüe, mas os resultados são sempre mostrados por par de línguas, a original do texto e a da tradução. Quando a expressão ou o termo pesquisado é encontrado nestes segmentos, a ferramenta os 
apresenta de maneira alinhada em duas colunas: a primeira contém os segmentos originais e a segunda contém as traduções correspondentes. Isso dará ao usuário uma idéia de como a expressão ou o termo tem sido traduzido até então, indicando assim provavelmente um padrão ou tendência de tradução, que pode Ihe ajudar a se convencer de que uma escolha é mais acertada que outra. É importante observar, neste sentido, que este tipo de ferramenta deve em geral ser utilizado como complemento, e não substituto, de dicionários eletrônicos e bases de dados terminológicas. Geralmente será em um momento de dúvida do intérprete, quando, mesmo após ter consultado estes recursos, ele ainda não conseguiu se decidir pela utilização de uma ou outra forma de tradução, que a TM se mostrará de muita valia.

O Linguee é um exemplo de TM rico em conteúdo e disponível na internet gratuitamente. Ele foi desenvolvido em 2009 por uma empresa privada alemã de mesmo nome e oferece atualmente traduções entre o inglês e outras quatro línguas: português, francês, alemão e espanhol. Segundo o informado no website desta ferramenta, a maior parte do conteúdo da sua base de dados provém de websites bilíngües de empresas, organizações e universidades, cujas traduções foram feitas por profissionais. Além disso, outras fontes mencionadas são documentos da União Européia e especificações de patentes (Linguee, 2012).

Podemos simular que um intérprete necessita de uma tradução para "think tank", e se encontra indeciso sobre qual seria a melhor solução. Ao pesquisarmos esta expressão no Linguee, a ferramenta nos mostra como resultado 12 segmentos onde o termo é traduzido como "grupo de reflexão", 2 segmentos onde o termo é traduzido como "célula de reflexão" e diversos outros de ocorrência única, onde há traduções tão distintas como "laboratório de idéias", "grupo de estudo", ou ainda outro onde se mantém a expressão em inglês. Isso pode indicar ao intérprete que estivesse em dúvida entre a utilização de "grupo de reflexão" ou "laboratório de idéias", por exemplo, que a primeira opção parece ser a mais acertada porque é a solução mais empregada por tradutores. É importante observar aqui, no entanto, que este critério, por si só, não é garantia de acerto na escolha. Se, por acaso, o intérprete vai se dirigir a um público que já incorporou "think tank" no seu jargão normal de trabalho, o melhor seria repetir a expressão no original. 


\begin{tabular}{|c|c|}
\hline 楼 English & Q. Portuguese \\
\hline \multirow[t]{2}{*}{$\begin{array}{l}\text { To achieve a better understanding of the impact of } \\
\text { reduced rates, the Directive also lays down that the } \\
\text { Commission must prepare an assessment report, on } \\
\text { the basis of a study carried out by an independent } \\
\text { economic think-tank, on the impact of reduced rates } \\
\text { applied to locally supplied services, notably in terms of } \\
\text { job creation, economic growth and the proper } \\
\text { functioning of the internal market. } \quad \mathrm{G} \text { eur-lex.europa.eu }\end{array}$} & $\begin{array}{l}\text { [...] das taxas reduzidas, a directiva prevê ainda a } \\
\text { apresentação, o mais tardar em } 30 \text { de Junho de } 2007 \text {, } \\
\text { de um relatório de avaliação da Comissão, baseado } \\
\text { num estudo elaborado por um grupo de reflexão } \\
\text { independente na área da economia, sobre o impacto } \\
\text { das taxas reduzidas aplicadas aos serviços prestados } \\
\text { localmente, nomeadamente na criação de emprego, } \\
\text { crescimento económico e bom funcionamento do }\end{array}$ \\
\hline & $G$ eur-lex.europa.eu \\
\hline $\begin{array}{l}{[\ldots] \text { representatives of the Russian Federation to }} \\
\text { participate in the HIVIAIDS Think Tank and the Civil }\end{array}$ & $\begin{array}{l}\text { [...] representantes da Federação Russa a participar } \\
\text { no Grupo de Reflexão sobre VIH/SIDA e no Fórum da }\end{array}$ \\
\hline$G \rightarrow$ eur-lex.europs.eu & $G \rightarrow$ eur-lex.europa.eu \\
\hline $\begin{array}{l}\text { I welcome the establishment of a think-tank to provide } \\
\text { guidelines to the Commission on the social, cultural } \\
\text { and political context as regards the selection of } \\
\text { projects and complementary actions which will aid the }\end{array}$ & $\begin{array}{l}\text { Saúdo a criação de uma célula de reflexão incumbida } \\
\text { de formular orientações à Comissão sobre o contexto } \\
\text { social, cultural e político no que respeita à selecção } \\
\text { dos projectos e acções complementares, o que muito }\end{array}$ \\
\hline Daphne $[\ldots] \quad \quad G$ europarl.europs.eu & ajudará [...] $\quad G$ europarl.europa.eu \\
\hline $\begin{array}{l}\text { We have a think-tank where everybody is involved: they } \\
\text { have discussions and exchange best practice and }\end{array}$ & \multirow{2}{*}{ 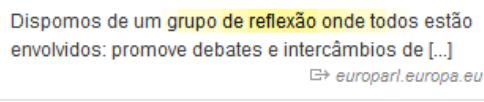 } \\
\hline experiences. $\quad G \rightarrow$ europarl.europs.eu & \\
\hline $\begin{array}{l}\text { This think-tank shall be able to define a specific annual } \\
\text { action plan and jointly monitor its implementation, } \\
\text { particularly in the context of the contribution of the } \\
\text { Partnership Agreement to the implementation of }\end{array}$ & \multirow[t]{2}{*}{$\begin{array}{l}\text { Este grupo de reflexão pode definir um plano de acçãa } \\
\text { anual especifico e acompanhar de comum acordo a } \\
\text { sua execução, nomeadamente no âmbito da } \\
\text { contribuição do Acordo de Parceria para a execução } \\
\text { da política sectorial das pescas da }\end{array}$} \\
\hline \multirow[t]{2}{*}{ Mauritania's [...] } & \\
\hline & Mauritânia. $\quad \mathrm{G}$ eur-lex.europa.eu \\
\hline $\begin{array}{l}\text { This amendment proposes to establish a "think tank" } \\
\text { to provide guidelines and orientations in order to } \\
\text { facilitate the priorities for the selection of } \\
\text { projects. }\end{array}$ & $\begin{array}{l}\text { Esta alteração propõe que seja constituido um grupo } \\
\text { de reflexão para fornecer directrizes e orientações, a } \\
\text { fim de facilitar a escolha de prioridades [...] } \\
\square \text { eur-lex.europa.eu }\end{array}$ \\
\hline
\end{tabular}

Figura 7: Resultado parcial do Linguee para a pesquisa do termo "think tank".

\subsection{Conclusão}

Como pudemos ver, as ferramentas e recursos que podem ser explorados na etapa de preparação do intérprete para um evento são vários e complementares. É na composição das diferentes funcionalidades que o intérprete poderá obter os melhores benefícios. Nos cursos de interpretação, algumas destas ferramentas já são explicadas e utilizadas habitualmente pelos professores durante os exercícios práticos. Certamente devido a este estímulo, e igualmente pelo exemplo dos seus pares, a maioria dos intérpretes atualmente já integrou uma ou outra das soluções apresentadas, senão um conjunto delas, na sua rotina de trabalho. No entanto, o que pode ser observado em campo é que os intérpretes ainda se encontram longe de aproveitar todo o potencial destas soluções. Isso talvez se deva ao fato de que tanto formadores como profissionais experientes, que têm muita influência neste mercado, não dêem à tecnologia a merecida importância e foco como material de apoio ao trabalho da interpretação. 


\section{Soluções tecnológicas transformadoras do ambiente de trabalho}

Sempre que nos referimos à interpretação simultânea, imaginamos a cabine onde os intérpretes desenvolverão o seu trabalho. Esta cabine pode ser de diversos tipos e tamanhos, incluindo as portáteis, que podem ser transportadas e instaladas em qualquer ambiente improvisado como sala de conferências, e as que são construídas como parte integrante de uma sala já projetada para este fim. Em ambos os casos, no entanto, as cabines deverão estar sempre isoladas física e acusticamente através de seus painéis e paredes, porém permitindo aos intérpretes uma visão ampla e direta da mesa de conferência. As cabines também deverão ser equipadas com os aparelhos de transmissão e recepção de som, que consistem basicamente em microfones, fones de ouvido e uma caixa ou painel de controle que permitirá aos intérpretes, entre outras coisas, ajustar o volume do áudio, ligar (on), desligar (off) ou simplesmente silenciar (mute/cough) o microfone durante alguns segundos.

Esta quase inevitável associação que fazemos entre a cabine e o exercício da interpretação simultânea se deve ao fato de que foi esta tecnologia que permitiu a popularização e propagação desta modalidade de interpretação. Talvez o principal marco histórico da interpretação simultânea seja o Julgamento de Nuremberg, para o qual a IBM recebeu a incumbência de desenvolver um sistema apropriado em que cinco canais de áudio estavam disponíveis para o público e os membros do tribunal: um canal para o orador e os demais para interpretações em língua inglesa, russa, francesa e alemã (Language Outreach by the UN, 2012). Até então, ainda que na Liga das Nações já estivesse em uso desde 1931 um sistema de tradução simultânea, igualmente desenvolvido pela IBM, as conferências internacionais operavam principalmente na modalidade consecutiva (TAYLOR-BOULADON, 2007, p.20).

Atualmente, no entanto, vemos surgir novas tecnologias que estão, pouco a pouco, permitindo a configuração de novos ambientes de trabalho que ultrapassam as restrições do espaço físico, sendo esta uma das principais limitações que impõe a cabine de interpretação. Com um ritmo muito acelerado de desenvolvimento e assimilação por parte do mercado, estas tecnologias, por outro lado, também nos 
permitem vislumbrar novos cenários virtuais para o exercício da interpretação num futuro não muito distante.

\subsection{Equipamento Portátil de Interpretação}

O equipamento portátil de interpretação pode ser considerado o primeiro e mais simples passo fora da cabine, sendo constituído por aparelhos transmissores e receptores de pequeno tamanho, que operam sem fio. Assim, este equipamento dá aos seus usuários uma mobilidade que não é permitida com a cabine. Os aparelhos transmissores serão utilizados pelos intérpretes, enquanto que os receptores serão utilizados pelos participantes do evento, sejam eles oradores ou não. Os receptores são similares aos empregados em interpretação simultânea com cabine, possuindo um seletor de canais e outras funcionalidades. As condições de trabalho com o uso deste equipamento ficam prejudicadas para o intérprete, no entanto, principalmente pela inexistência de um isolante acústico, como o oferecido pela cabine, e a necessidade de deslocamento constante, se foi este o motivo de não se ter optado pelo uso da cabine. Isso pode causar inclusive um impacto na qualidade da interpretação.

Recomenda-se o uso deste equipamento apenas para eventos informais, de pequeno porte e curta duração, em que a mobilidade seja inevitável e a interação entre os participantes seja pequena, pois os aparelhos receptores utilizados por estes não podem transmitir áudio para o aparelho transmissor do intérprete. Assim, eventos que envolvem sessões de debates e de perguntas e respostas não devem usar esta solução (GEN - Global Equipment Network, 2012).

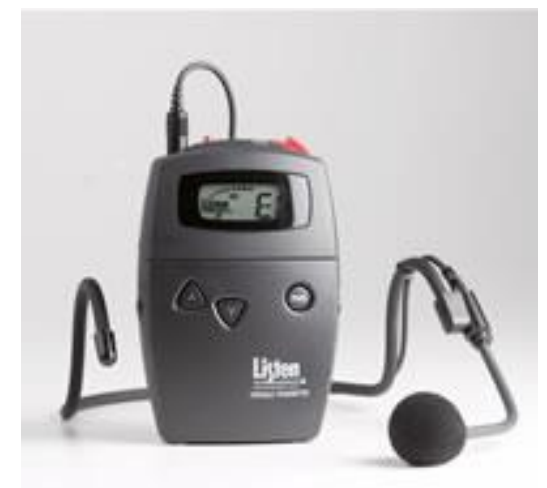

Figura 8: Aparelho transmissor utilizado pelo intérprete 


\subsection{Vídeo-Conferência}

A vídeo-conferência é apenas uma das soluções, porém certamente a mais moderna, que a tecnologia disponibiliza para um problema que já é antigo para os intérpretes: a necessidade de se realizar uma interpretação remota ou à distância. Este problema existe desde os tempos em que chefes de estado precisaram se comunicar por telefone (dando ensejo à interpretação por telefone), em que canais de televisão começaram a transmitir ao vivo programas estrangeiros (dando ensejo à interpretação pela televisão), assim como em outras situações em que o intérprete não podia estar fisicamente presente onde se encontravam os oradores, seja devido a uma impossibilidade logística, financeira ou de qualquer outra natureza. Faz-se necessário ressaltar aqui que a interpretação remota, no contexto deste trabalho, só se configura quando o intérprete não está no mesmo ambiente físico de um ou mais oradores. Quando quem está longe é apenas ouvinte desta interpretação, seja o público ou parte dele, ou mesmo outros membros da conferência, não é o caso de se falar em interpretação à distância.

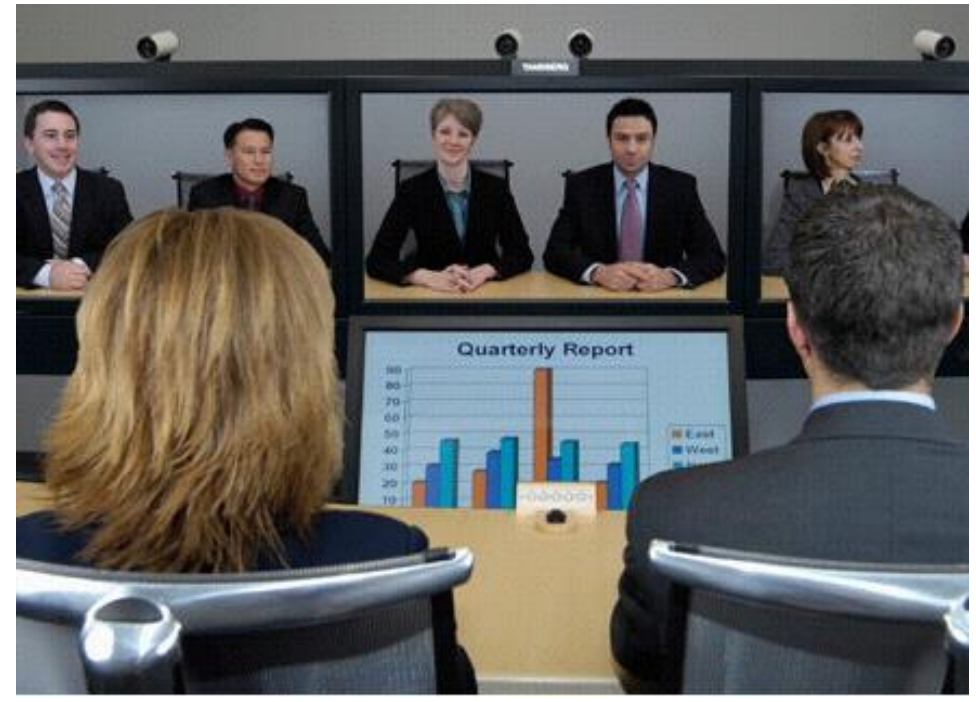

Figura 9: A vídeo-conferência permite contato visual e auditivo com pessoas situadas em lugares remotos, simulando um encontro real.

$\mathrm{Na}$ vídeo-conferência há um ou mais participantes situados em um ou mais lugares distintos (sempre em referência ao intérprete), mas todos conectados entre si através de canais de áudio e vídeo. O intérprete vai então realizar o seu trabalho observando os oradores pelos canais de vídeo e os ouvindo pelos canais de áudio. 
Ao interpretar, a voz do intérprete será transmitida por um canal de áudio distinto do de entrada, caso contrário não seria possível realizar uma interpretação simultânea, ficando o intérprete limitado a uma interpretação consecutiva. Se por um acaso não houver canais de vídeo, estando disponíveis apenas os de áudio, se tratará de mera interpretação por telefone, ainda que com o uso de diferentes canais seja possível realizar uma interpretação simultânea. Pois a grande vantagem que a tecnologia da vídeo-conferência apresenta é justamente permitir que os diversos membros do evento estejam conectados pelos sentidos da visão e audição, como se estivessem compartilhando o mesmo espaço físico, ainda que se encontrem a quilômetros de distância.

Devido principalmente à importância, já amplamente reconhecida, do contato visual, direto e não-intermediado entre intérprete e orador, como fator determinante da qualidade da interpretação, vem se desenvolvendo já há algum tempo no meio profissional um sério debate sobre a utilização da vídeo-conferência como um meio legítimo de interpretação. A principal pergunta que se quer responder é, em resumo, se a inexistência de proximidade física pode prejudicar a qualidade da interpretação a ponto de se determinar que as condições de trabalho não são aceitáveis. No entanto, a vídeo-conferência é atualmente uma realidade no mercado da qual não podemos escapar, já que nem sempre todos os participantes de um evento podem estar presentes fisicamente, ou simplesmente o patrocinador não dispõe dos meios financeiros para reuni-los a todos num mesmo lugar, principalmente quando se trata de evento de business em que, por exemplo, uma multinacional busca reunir todos ou vários de seus empregados situados em várias cidades ao redor do mundo para realizar um evento corporativo. Ao mesmo tempo, realizar uma vídeo-conferência via internet se tornou uma tarefa muito simples e barata, acessível a qualquer um, principalmente devido a ferramentas como o Skype. A imposição cada vez maior desta tecnologia talvez seja o motivo pelo qual alguns autores, tratando desta temática, tenham buscado flexibilizar um pouco a terminologia, definindo a vídeoconferência, no contexto da interpretação, como simplesmente aquela situação em que apenas uma minoria de participantes se encontra em lugar remoto (BERBERIRABIEN, 2010, p. 71). Em contrapartida, quando é a maioria dos participantes que se encontra em lugar remoto, se trataria de interpretação remota. Segundo esta visão, a primeira seria legítima, enquanto que a segunda deveria ser considerada inaceitável. Neste trabalho, no entanto, não se vê motivo para se definir o termo em 
função do número de oradores de um lado ou do outro da conexão midiática, mas sim em função da natureza e uso desta conexão. Também não está no escopo deste trabalho discutir a legitimidade da vídeo-conferência como meio de interpretação, mas apenas comprovar a sua influência contemporânea como agente modificadora do ambiente de trabalho dos intérpretes. ${ }^{14}$

\subsection{Virtual Interpreting Environment (VIE)}

Aqui deixamos mais uma vez de nos ater apenas àquelas soluções que já se encontram no mercado, ainda que não amadurecidas o suficiente, e começamos a contemplar aquilo que o futuro provavelmente nos reserva, sempre, claro, a partir de tendências concretas e não simplesmente de uma imaginação fértil. Neste sentido, ainda não se dispõe de qualquer ferramenta de VIE no mercado digna de nota, mas o tema já é abordado no meio acadêmico e há inclusive projetos que se propõem a materializar esta idéia.

Um VIE, como qualquer outro VE (Virtual Environment), é basicamente um ambiente virtual que busca simular um ambiente real, utilizando computação gráfica de ponta para reproduzir todos os objetos em 3D. Tais objetos possuem proporções, texturas e animações capazes de oferecer uma experiência muito realista, enquanto que os usuários, por sua vez, são representados por avatares, ou seja, figuras que são criadas à sua imagem e semelhança. Quanto mais avançado for o VE, maior será a capacidade de se modelar o avatar de acordo com as características físicas do usuário, assim como também será mais fiel a reprodução dos seus movimentos e expressões faciais. Os campos da tecnologia que se encontram à frente no desenvolvimento e uso desta tecnologia são os jogos de console e as redes sociais. No primeiro caso temos, por exemplo, o XBox, que utiliza a tecnologia Kinect, um potente sensor de movimentos desenvolvido pela Microsoft. No que se refere às redes sociais, temos o Second Life (SL), que talvez seja a experiência mais importante e abrangente até o momento de interação social em ambientes virtuais, principalmente porque funciona na internet, com acesso gratuito e irrestrito. O voice chat (bate-papo com voz) entre avatares foi

\footnotetext{
${ }^{14}$ A própria Associação Internacional de Intérpretes de Conferência (AIIC), organismo que rege as normas e a ética da categoria, publicou uma diretriz sobre o assunto intitulada "Guidelines for Remote Conferencing", além de já ter publicado igualmente diversos artigos de colaboradores que corroboram essa tendência.
} 
disponibilizado no SL em versões mais recentes, fazendo com que diversos eventos já promovidos neste $\mathrm{VE}$, como cursos e debates, freqüentados por pessoas de todo o mundo, tornem esta experiência um interessante laboratório de estudos para se verificar a viabilidade de um VIE.

Annalisa Sandrelli e Jim Hawkins opinam ${ }^{15}$ que o VIE seria o próximo passo na área, baseado em tecnologia já disponível na indústria dos jogos, permitindo uma redução massiva dos custos envolvidos na produção de um evento de grande porte (SANDRELLI e HAWKINS, 2006). Eles também arriscam um palpite sobre quais seriam os componentes básicos deste novo modelo de simulador, que deveria ter pelo menos um console para oradores, outro para intérpretes e também um painel de controle. Ao descrever as funcionalidades mínimas de cada console, eles incluem no console virtual para intérpretes todos os controles a que o intérprete já está acostumado no mundo físico (on/off, mute/cough, etc.).

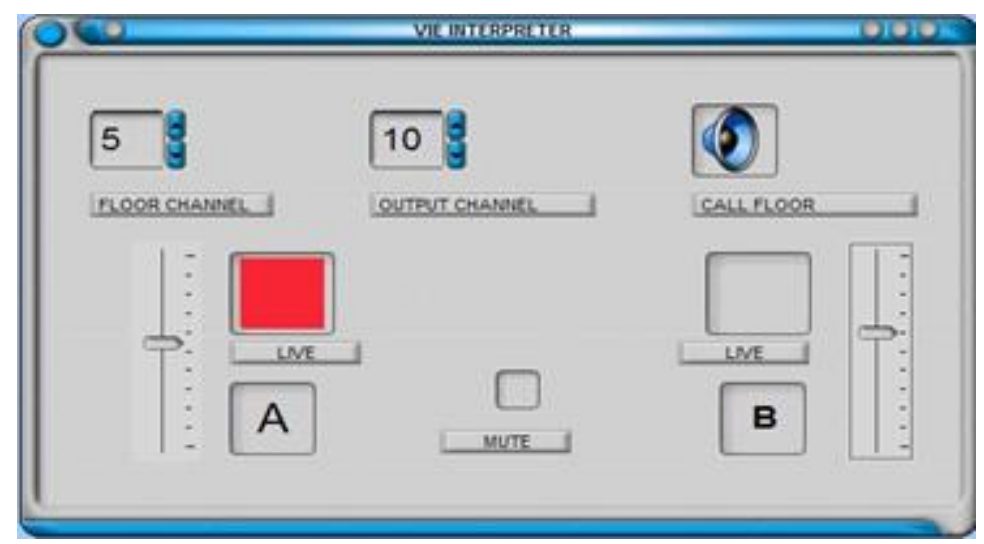

Figura 10: O console para intérpretes, segundo Annalisa Sandrelli e Jim Hawkins.

É evidente que a VIE traz à superfície novamente toda a discussão sobre a legitimidade de ambientes de trabalho para interpretação remota. Principalmente porque, com o ambiente virtual, o contato entre o intérprete e o orador se degrada ainda mais. Se, quando falamos da vídeo-conferência, vimos que o contato visual é mediado e, justamente por isso, alvo de muitas críticas, no caso da VIE ele passa simplesmente a inexistir. O que o intérprete veria, neste caso, seria apenas o corpo

\footnotetext{
${ }^{15}$ Sandrelli, da Universidade de Bolonha, e Hawkins, da Melissi Multimedia Ltd., realizaram uma apresentação intitulada "From Black Box to VIE: another step in the development of CAIT" na Universidade de Westminster, entre 30 de junho e 1 de julho de 2006, onde expuseram estas idéias.
} 
do avatar, cujo rosto certamente não reproduziria com perfeição todas as inúmeras expressões faciais e os movimentos labiais do ser humano que busca representar (considerando-se, claro, a tecnologia atualmente disponível). Sabemos que toda esta animação facial é uma fonte muito rica de informações para os intérpretes, e pode Ihes ajudar a dar soluções plausíveis em situações onde o áudio sozinho não resolve. Por outro lado, seriam tantas as vantagens criadas por esta tecnologia, principalmente se baseada numa plataforma universal como a internet, que seria quase inevitável considerá-la como uma alternativa viável em certos casos. Para os patrocinadores do evento, seria uma oportunidade de reduzir custos e convidar mais participantes; para os organizadores, seria a solução de todos os problemas logísticos, passando o foco para questões de natureza tecnológica; para o público, seria a facilidade de acesso a eventos no mundo inteiro, possivelmente sem custo; e, finalmente, para os intérpretes, seria a possibilidade de acesso a um mercado global.

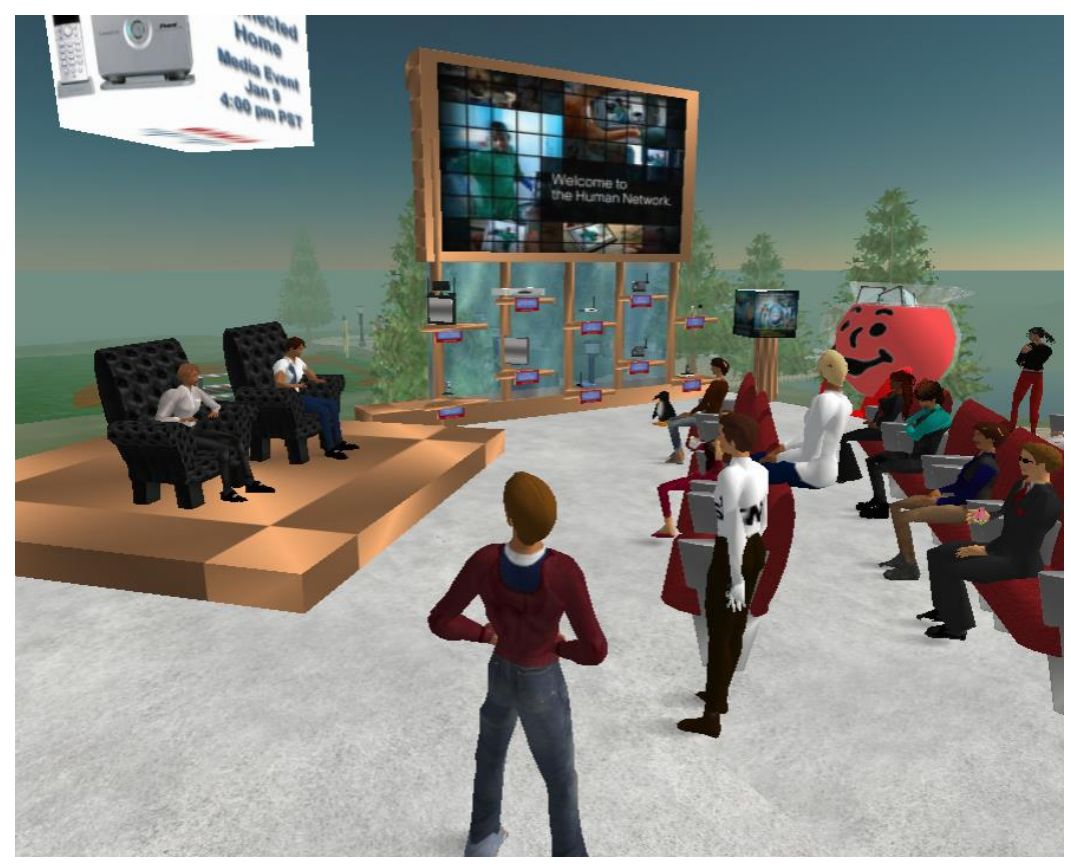

Figura 11: Evento realizado no Second Life

\subsection{Sistemas de Reconhecimento da Fala}

Os sistemas de reconhecimento da fala são conhecidos igualmente pelas expressões em inglês Automatic Speech Recognition (ASR) e Speech to Text (STT). 
Para simplificar, será utilizada a partir daqui apenas a sigla ASR. Apesar desta tecnologia já ter uma longa história de pesquisa e desenvolvimento, é bem recente o seu emprego em larga escala, e hoje já encontramos diversos produtos no mercado que a utilizam, sendo o Dragon Naturally Speaking um dos mais conhecidos. A ASR é atualmente empregada na criação de interfaces de usuário baseadas na voz, principalmente naqueles aplicativos que mais podem se beneficiar desta facilidade: jogos, e-mails para smartphones, soluções de domótica ${ }^{16}$, sistemas de telefonia e editores de texto, entre outros. Sem dúvida alguma, os usuários mais beneficiados com esta tecnologia são aqueles que têm uma deficiência que faz da digitação uma tarefa árdua ou mesmo impossível.

A ASR só se tornou mais popular recentemente porque antes a tecnologia não estava amadurecida o suficiente para a exploração comercial. Foram muitos os desafios que os pesquisadores tiveram que enfrentar e superar para que a máquina fizesse aquilo que para nós, humanos, é tão simples e natural: captar e reconhecer os fonemas emitidos por um interlocutor, reagrupando-os em seguida para formar palavras existentes, e transcrevendo estas últimas para formar um texto que faça sentido. Contudo, não faz parte do escopo deste trabalho descrever tais problemas, nem explicar suas soluções. Faz-se apenas necessário reconhecer que foi um longo caminho, que ainda está longe de chegar ao fim, pois há ainda muito a ser feito para aperfeiçoar esta tecnologia.

O aproveitamento da ASR na interpretação ainda não acontecerá tão cedo. Primeiramente, porque os aplicativos que empregam esta tecnologia atualmente têm um objetivo muito mais modesto. Em geral, estão projetados para interpretar comandos curtos de voz ou, no máximo, no caso de texto livre, o vocabulário deverá ser limitado ${ }^{17}$ e a narração mais lenta e pausada do que o normal. Além disso, como a fala varia consideravelmente de pessoa para pessoas (entonação, timbre de voz, etc.), para minimizar os erros as máquinas deverão primeiro "treinar" com a voz do locutor (Dragon Naturally Speaking, 2012). Somente uma vez que o sistema tenha sido suficientemente verificado e corrigido em relação às suas escolhas na interpretação da fala, é que poderá ser usado de maneira prática, com um grau

\footnotetext{
${ }^{16}$ Domótica é o conjunto de tecnologias que permitem a administração, local ou remota, de diversos recursos de uma casa (temperatura, luzes e eletrodomésticos em geral).

${ }^{17}$ No exemplo apresentado aqui, o Dragon Naturally Speaking, é um produto com versões formatadas para as áreas médica, legal e corporativa.
} 
aceitável de erros. Assim sendo, o discurso livre de conteúdo e forma, praticado por várias pessoas, que é tão típico dos eventos que requerem o trabalho de intérpretes, ficaria excluído atualmente do universo de aplicações práticas da ASR. No entanto, como a tecnologia se desenvolve cada vez mais rapidamente, não é nada difícil prever um futuro, talvez não muito distante, em que os discursos de diferentes interlocutores, mesmo complicados pela distorção de diferentes sotaques e às vezes emaranhados em debates, possam ser apreendidos e transcritos na tela de um computador.

Cabe agora nos perguntar: qual seria a verdadeira utilidade para o intérprete de se ter um discurso transformado em texto? A primeira e mais óbvia vantagem de se poder contar com um texto de apoio seria a possibilidade de, em caso de dúvida, verificar uma ou outra palavra pronunciada pelo orador ou até, em casos extremos (problemas no áudio, sotaque muito carregado, etc.), realizar um sight-translation. $\mathrm{O}$ mais provável, no entanto, é que a ASR fosse combinada com outras soluções já disponíveis no mercado atualmente, gerando assim sistemas com funcionalidades mais avançadas para o intérprete. Podemos imaginar então uma solução que faça a integração da ASR com um glossário eletrônico como, por exemplo, o Interplex, já comentado anteriormente. Neste caso, cada palavra do orador seria captada pela ASR, mas não imediatamente transcrita para a tela do computador. Ela primeiro seria pesquisada de maneira automática no glossário do intérprete e, somente se a entrada correspondente fosse encontrada, seriam exibidas a palavra e a tradução correspondente. É interessante notar que aqui se trata de uma solução de apoio mediadora, pois se interpõe como filtro, fazendo um trabalho de mediação, entre o orador e o intérprete.

\subsection{Conclusão}

Como pudemos observar nesta seção, algumas das soluções tecnológicas apresentadas têm consequências notáveis no ambiente de trabalho do intérprete, seja removendo as barreiras físicas estabelecidas pela cabine de interpretação, seja pela introdução de ferramentas que operariam durante a interpretação, oferecendo funcionalidades que podem ter um impacto muito positivo no seu desempenho.

A cabine é, e provavelmente continuará sendo durante muito tempo, a solução tradicional que se mostrou mais adequada, desde o momento histórico em 
que os encontros internacionais de caráter político se tornaram uma realidade. No entanto, atualmente, vemos que eventos internacionais das mais diversas naturezas são cada vez mais numerosos, como conseqüência principalmente da globalização e de seus diversos efeitos, seja no âmbito econômico ou político. É quase inevitável pensar, assim, que um novo leque de soluções tecnológicas deverá surgir para permitir que as pessoas participem desses eventos sem precisar, para isso, realizar deslocamentos constantes. Se, por um lado, é verdade que a vídeo-conferência e as ferramentas de VIE podem causar um certo grau de deterioração na qualidade da interpretação, por outro lado poderemos no futuro também contar com soluções mediadoras, como aquelas baseadas na ASR, que vão proporcionar uma melhora na qualidade da interpretação, equilibrando assim novamente o campo de jogo. 


\section{Considerações Finais}

Como pudemos observar, a tecnologia teve um papel preponderante, com o advento da cabine, desde que a interpretação de conferências adquiriu relevância no cenário internacional e se tornou uma profissão reconhecida, aproximadamente há 80 anos. Na formação dos intérpretes, com os cursos que foram surgindo com o tempo para responder a esta demanda de novos profissionais, a tecnologia também sempre se mostrou de grande ajuda, principalmente com o uso de diferentes mídias de gravação e reprodução de áudio. Desde então, sabemos o quanto a tecnologia já evoluiu, especialmente nessas últimas décadas, causando um grande impacto em praticamente todas as profissões, pois, afinal, podemos dizer que a tecnologia se tornou ubíqua. No caso particular dos intérpretes, esta infiltração da tecnologia na rotina de trabalho pode ser observada em várias frentes, como foi possível verificar neste trabalho, ou seja, na formação, na preparação e no ambiente de trabalho. Mas isso tem sido motivado principalmente por dois fatores, sem os quais é provável que os profissionais de hoje, incluindo os intérpretes, não estivessem se beneficiando tanto dos últimos avanços. O primeiro fator é a disseminação do $\mathrm{PC}^{18}$ e, ultimamente, dos computadores portáteis (a última onda, com a chegada dos tablets, vai facilitar ainda mais a integração da máquina na rotina de trabalho). $O$ segundo fator é a invenção da internet, que nos últimos anos têm servido como grande facilitador e motivador na criação e no consumo de inúmeros novos recursos tecnológicos. Não é à toa que vimos que a maioria dos recursos mencionados neste trabalho encontra-se disponível na internet.

É interessante observar, no entanto, que apesar de toda essa evolução tecnológica, que foi capaz de multiplicar o ferramental à disposição dos intérpretes, transformando consideravelmente sua maneira de estudar e se preparar para eventos, não foi capaz de operar nenhuma revolução na cabine de interpretação. $A$ cabine se encontra hoje tão sólida como inicialmente foi projetada, nos primórdios dos tempos da interpretação. Apenas na história muito recente da tecnologia vemos algumas propostas que visam abrir este espaço, permitindo que os participantes de eventos, assim como os seus respectivos intérpretes, possam se reunir e trabalhar num ambiente virtual, ainda que estejam a milhares de quilômetros de distância uns

\footnotetext{
${ }^{18}$ Personal computer
} 
dos outros. A partir daqui é difícil prever se estas soluções realmente levarão a uma substituição da cabine, mas é fácil sugerir um prognóstico que inclui tais soluções como uma alternativa cada vez mais viável para situações em que a logística seja um verdadeiro empecilho. Isso é o que deve acontecer num futuro breve, segundo os movimentos que se percebem hoje. Num futuro mais distante, porém, fica bem mais complicado arriscar previsões. O mais provável, no entanto, é que o ambiente de trabalho, seja ele físico ou virtual, esteja mais aparelhado com recursos que vão apoiar o intérprete na realização da interpretação, como as soluções baseadas em tecnologia de reconhecimento de fala. Se aliarmos isso aos cada vez mais robustos tradutores automáticos, dotados de uma potente inteligência artificial, não fica difícil imaginar que, daqui a algumas décadas, os intérpretes poderão ter à sua disposição algumas ferramentas muito interessantes de apoio. Mas, é bom frisar, por enquanto servirão tão somente como um apoio, oferecendo boas sugestões de interpretação, por exemplo, e não como uma substituição ao trabalho do próprio intérprete. Pois não podemos ainda sequer conceber que o trabalho humano possa ser substituído inteiramente por uma eventual máquina interpretadora, de tão complexa e sofisticada que se mostra a tarefa. É certo que ainda nos encontramos muito longe disso, e qualquer exercício neste sentido torna-se puro jogo de adivinhação. 


\section{Índice Remissivo de Ferramentas e Recursos Tecnológicos}

YouTube, pág. 14

http://www.youtube.com/

TedTalks, pág. 14

http://www.ted.com/talks

Speech Repository, pág. 15

http://www.multilingualspeeches.tv/scic/portal/index.html

BlackBox, pág. 16

http://www.melissi.co.uk/software/BBx.html

Melissi Digital Language Lab (MDLL), pág. 18

http://www.melissi.co.uk/software/MDLL.html

MS Office (inclui o MS Word e o MS Excel), pág. 20

http://www.microsoftstore.com.br/shop/pt-BR/Microsoft/Office

Interplex, pág. 21

http://www.fourwillows.com/interplex.htm/

Merriam-Webster, pág. 22

http://www.merriam-webster.com

WordReference.com, págs. 22 e 25

http://www.wordreference.com

Encyclopaedia Britannica, pág. 22

http://www.britannica.com

Wikipedia, pág. 23

http://www.wikipedia.org 
IATE, pág. 24

http://iate.europa.eu

Linguee, pág. 26

http://www.linguee.com.br

Equipamento Portátil de Interpretação, pág. 29

http://www.globalav.com/portable.html

Skype, pág. 31

http://skype.com

Second Life, pág. 32

http://secondlife.com/whatis

Dragon Naturally Speaking, pág. 35

http://www.dragon-medical-transcription.com/index.htm 


\section{Bibliografia}

BENDAZZOLI, C.; SANDRELLI, A. An approach to Corpus-Based Interpreting Studies: Developing EPIC (European Parliament Interpreting Corpus). 2005. EU-HighLevel Scientific Conference Series. MuTra 2005 - Challenges of Multidimensional Translation: Conference Proceedings.

\section{BERBER-IRABIEN, D. C. Information and Communications Technologies in Conference} Interpreting. Universitat Rovira e Virgili. 2010.

CNN Money. Encyclopedia Britannica to Stop Printing Books. Artigo publicado em março de 2012. Disponível em: <http://money.cnn.com/2012/03/13/technology/encyclopediabritannica-books/index.htm> Acesso em maio de 2012.

Dragon Naturally Speaking. History of Speech Recognition and Transcription Software. Disponível em: <http://www.dragon-medicaltranscription.com/historyspeechrecognition.html> Acesso em maio de 2012.

GEN - Global Equipment Network. Portable Interpretation Systems. Disponível em: <http://www.globalav.com/portable.html> Acesso em maio de 2012.

IATE. About IATE. Disponível em: <http://iate.europa.eu/iatediff/about_IATE.html> Acesso em maio de 2012.

Language Outreach by the UN. History of Simultaneous Interpretation. Disponível em: <http://www.unlanguage.org/Careers/Interpret/COV/Simultaneous/default.aspx> Acesso em maio de 2012.

Linguee. Sobre o Linguee. Disponível em: <http://www.linguee.com.br/portuguesingles/page/about.php> Acesso em maio de 2012.

MA Conference Interpreting. London Metropolitan University. Disponível em: $<$ https://intranet.londonmet.ac.uk/prog-plan/postgrad-line/structures/conferenceinterpreting-ma-2012.cfm> Acesso em maio de 2012.

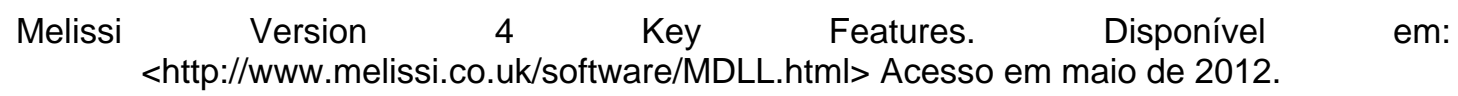

Melissi Virtual Interpreting Suíte (VIS). Disponível em: <http://www.melissi.co.uk/software/VIS.html> Acesso em maio de 2012. 
SANDRELLI, A. Designing CAIT (Computer-Assisted Interpreter Training) Tools: BlackBox. 2005. EU-High-Level Scientific Conference Series. MuTra 2005 Challenges of Multidimensional Translation: Conference Proceedings.

SANDRELLI, A.; HAWKINS, J. From Black Box to the Virtual Interpreting Environment (VIE): Another Step in the Development of Computer Assisted Interpreter Training. The Future of Conference Interpreting: Training, Technology and Research. University of Westminster. 2006.

Speech Repository project. What is it? Disponível em: $<$ http://www.multilingualspeeches.tv/scic/portal/index.html?project=true\#what> Acesso em maio de 2012.

TAYLOR-BOULADON, V. Conference Interpreting: Principles and Practice. $2^{\text {nd }}$ edition. BookSurge Publishing. 2007. 323p.

Wikipedia. About. Disponível em: <http://en.wikipedia.org/wiki/Wikipedia:About> Acesso em maio de 2012.

Wikipédia. Bem Vindo(a) à Wikipédia. Disponível em: <http://pt.wikipedia.org/wiki/Wikipédia:Página_principal> Acesso em maio de 2012. 